The surgical management of $M$ intracellulare infection with chronic empyema is not established. Yamamoto and associates ${ }^{1}$ reported a case of Mycobacterium avium complex infection in a patient with a chronic empyema, which was treated successfully with pleuropneumonectomy. They stated that lung resection might be performed for the surgical treatment of $M$ intracellulare infection with chronic empyema. Pleuropneumonectomy or lobectomy for chronic empyema, however, is very stressful. In our case, the $M$ intracellulare infection was cleared from the sputum after thoracic fenestration, and therefore we performed a thoracoplasty with an intrathoracic muscle flap transposition. This surgical treatment without lung resection in cases not involving $M$ intracellulare in the sputum is preferred because the procedure is less invasive, safer, and less stressful than surgical treatment with lung resection.

In our case, we selected a thoracoplasty with an intrathoracic muscle flap transposition. The residual lung changed into a honeycomb lung, which was unable to expand. If the residual lung had the ability to expand, air plombage would have been a better option than thoracoplasty with respect to respiratory function. ${ }^{3}$

GRFG glue is a new biologic adhesive agent with a better sealing efficacy. GRFG glue has strong adhesive properties (al- most 5 times that of fibrin glue). Several studies have reported the effectiveness of GRFG glue for the treatment of bronchial fistulas. ${ }^{4,5}$ Hasumi and colleagues ${ }^{4}$ reported the clinical experience of GRFG glue for acute empyema with bronchopleural fistula. GRFG glue is a useful agent for the treatment of bronchial fistulas.

\section{References}

1. Yamamoto H, Osako T, Aogauchi R, Yamamoto H, Hironaka S. Surgical treatment of Mycobacterium avium complex infection in a patient with chronic empyema. Nippon Geka Gakkai Zasshi. 1994;95:123-5.

2. Takemoto N, Kohiyama R, Tsuboi J, Sasaki K, Sakurabayashi I, Miyata M. A case of a patient with post-operative empyema due to Mycobacterium chelonae. Kyobu Geka. 1996;49:301-5.

3. Otsuka T, Imura Y, Yamamoto H, Sasano S. One case of chronic pyothorax with MRSA infection cured by air-plombage method. Kekkaku. 1999;74:513-7.

4. Hasumi T, Yamanaka S, Yamanaka H. Clinical experience of gelatinresorcin-formal (GRF) glue for acute empyema with broncho-pleural fistula. Kyobu Geka. 2003;56:82-5.

5. Umemori Y, Makihara S, Fukuhara T, Kotani K, Eda R. An effective case of a new biological adhesive agent, gelatin-resorcinol formaldehyde-glutaraldehyde glue (GRFG-glue) in treating refractory pulmonary fistula following lobectomy for pulmonary aspergilloma. Kyobu Geka. 1999;52:872-4.

\title{
Simultaneous traumatic rupture of bilateral pulmonary hydatid cysts
}

\author{
Berkant Özpolat, MD, ${ }^{\text {a }}$ Murat Sayın, MD, ${ }^{\text {b }}$ Orhan Veli Dogan, MD, ${ }^{a}$ and Yusuf Dogan, MD, ${ }^{\mathrm{b}}$ Ankara, Turkey
}

$\mathrm{H}$ ydatid disease is common in Turkey, and it is a serious problem of worldwide importance. Because of the elastic properties of the lung, it seldom shows signs and symptoms. The cysts are generally detected on routine examinations incidentally or when they are complicated. All hydatid cysts carry a risk of rupture, which is the most common complication, and trauma is a one of its causes. ${ }^{1,2}$

Here we present a life-threatening complication of traumatic bilateral ruptured hydatid cysts causing simultaneous bilateral pneumothorax. To our knowledge, this bilateral rupture is the first case reported in the English literature.

\footnotetext{
From the Departments of Cardiovascular Surgery ${ }^{\mathrm{a}}$ and Anesthesia and Reanimation, ${ }^{\mathrm{b}}$ Ministry of Health Diskapi Training and Research Hospital, Ankara, Turkey.

Received for publication March 3, 2005; accepted for publication March 28, 2005.

Address for reprints: Orhan Veli Dogan, MD, Esat Caddesi 105/14, Küçükesat 06660, Ankara, Turkey (E-mail: orhanv@yahoo.com).

J Thorac Cardiovasc Surg 2005;130:908-9

$0022-5223 / \$ 30.00$

Copyright $\odot 2005$ by The American Association for Thoracic Surgery

doi:10.1016/j.jtcvs.2005.03.028
}

\section{Clinical Summary}

A 20-year-old man was brought to the emergency department after a vehicle accident. He had diminished bilateral breath sounds and diffuse bronchospasm on auscultation. He was cyanotic and severely dyspneic. The computed tomographic (CT) scan of the thorax performed at the emergency department revealed bilateral pneumothorax and bilateral linear fibrotic densities in both lungs (Figure 1).

Bilateral chest tube insertion was performed immediately. After tracheal intubation, mechanical ventilation was started because of acute respiratory failure. The patient was transferred to the intensive care unit, and the mechanical ventilation was continued for 2 days. Steroid therapy was given to relieve the bronchospasm. After the expansion of both lungs, a new CT scan was performed, showing thin-walled, air-filled cavities in bilateral lobes with collapsed membranes that were specific for ruptured hydatid cysts (Figure 2). Serologic test results for hydatid disease were positive.

Chest tubes were removed at the 10th and 14th days after the expansion of both lungs, and the patient was discharged on the 17 th day. Albendazole $\left(10 \mathrm{mg} \cdot \mathrm{kg}^{-1} \cdot \mathrm{d}^{-1}\right)$ therapy was started as soon as the rupture was diagnosed, and it was continued for 6 months. No cavitary or pleural complications were observed at the 6-month examination. 


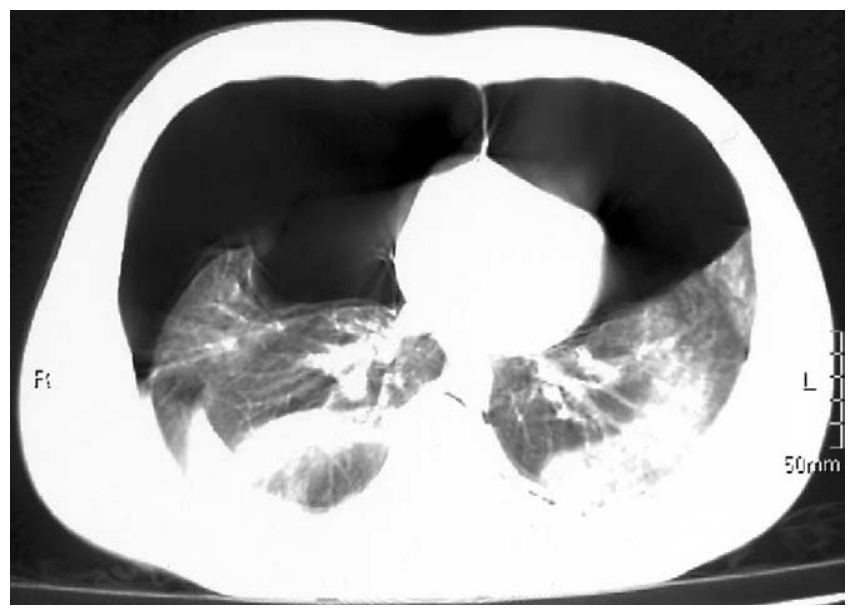

Figure 1. CT scan performed at the emergency department showing bilateral pneumothorax.

\section{Discussion}

Most patients with hydatid cysts are asymptomatic. Cyst rupture might be seen spontaneously or as a result of trauma. Nontraumatic unilateral pneumothorax incidence was reported to be between $2.4 \%$ and $6.2 \%$ of patients with hydatid cysts, and only one case of unilateral traumatic pulmonary rupture was reported. ${ }^{1,2}$ As far as we know, this is the first case of bilateral traumatic rupture of hydatid cyst with bilateral pneumothorax in the English literature.

Rupture into the pleural cavity usually causes pneumothorax, pleural effusion, or empyema, and it can lead to fatal allergic and anaphylactic reactions. ${ }^{1,2}$

Simultaneous bilateral pneumothorax is an extremely uncommon clinical event, and it is often fatal. Early diagnosis and treatment is critically important for the outcome. ${ }^{3}$ In our case simultaneous bilateral pneumothorax was managed by chest tube drainage and mechanical ventilation caused by acute respiratory failure.

CT is a valuable imaging method for visualization of collapsed membranes. The first CT performed at the emergency department demonstrated bilateral collapsed lungs and linear densities mimicking atelectasis after the expansion of lungs, and the second CT showed bilateral thin-walled cavities partly filled with air and folded germinative membrane, which is typical for ruptured pulmonary hydatid cyst. ${ }^{4}$

Surgical intervention is still the main modality for the treatment of hydatid disease. However, in endemic areas the disease affects younger age group, and after treatment, there is a reinfection risk.

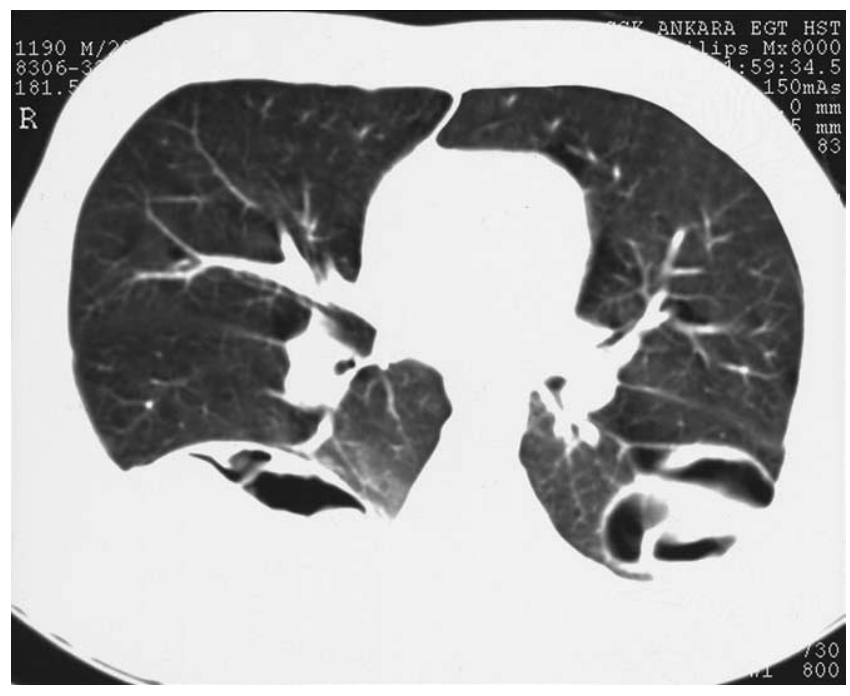

Figure 2. CT scan showing ruptured hydatid cysts. Huge cavities are seen in both lobes, with layering of collapsed hydatid germinative membranes.

Therefore, it is important to always use the most conservative surgical methods possible. ${ }^{1,2}$ In this case of traumatic rupture, bilateral tube thoracostomy was used as a conservative approach. Chemotherapy is added to avoid recurrence. No cavity complications occurred during the 6-month period.

This case report demonstrates that traumatic hydatid cyst rupture can cause bilateral pneumothorax, which is life-threatening, and therefore it should be included in the differential diagnosis of bilateral pneumothorax where the disease is endemic. In this case of traumatic rupture, conservative treatment was used successfully, and no late cavitary or pleural complications were seen.

\section{References}

1. Kuzucu A, Soysal Ö, Özgel M, Yologlu S. Complicated hydatid cysts of the lung: Clinical and therapeutic issues. Ann Thorac Surg. 2004;77: $1200-4$.

2. Gunay K, Taviloglu K, Berber E, Ertekin C. Traumatic rupture of hydatid cysts: a 12-year experience from an endemic region. J Trauma. 1999;46:164-7.

3. Sunam G, Gök M, Ceran S, Solak H. Bilateral pneumothorax: A retrospective analysis of 40 patients. Surg Today. 2004;34:817-21.

4. Maden N, Oyar O, Tekin U, Ozer H. Ruptured pulmonary hydatid cyst and folded membrane on CT. AJR Am J Roentgenol. 1992;158: 687. 